\title{
Game Analysis between Local Government and Developers in the Exploitation of Tourism Scenic Spots
}

\author{
Xixi Hu \\ Jinan University Management School, Guangzhou, China \\ Email: 906153552@qq.com \\ Received 20 January 2015; accepted 8 February 2015; published 11 February 2015 \\ Copyright (C) 2015 by author and Scientific Research Publishing Inc. \\ This work is licensed under the Creative Commons Attribution International License (CC BY). \\ http://creativecommons.org/licenses/by/4.0/ \\ (c) (i) Open Access
}

\begin{abstract}
This paper analyzes the balance of interests in scenic spots development by using the Game theory model. Based on the balancing process of decision-making behavior and interests of both parties, this paper builds a game model of balance of interests in tourism scenic spots. At last, it puts forward the solution countermeasures.
\end{abstract}

Keywords

Local Government, Developers, Tourism Scenic Spots Exploitation, Balance of Interests

\section{Introduction}

With the continuous increasing of economy and the growing of population, all relevant tourism industries have enjoyed a huge development. The statistic shows that the total income of China's tourism industry was 2.57 trillion yuan in 2012, with a growth rate of $14 \%$ year-on-year. Thus, with the expanding demand of the tourism industry and the plenty resources of China's land, the development benefits of tourism resources are distinct and attracting more and more investment. These days there are several large tourism scenic spots are exploiting, and other 2nd and 3rd phase of the tourism scenic projects are countless. However, a series of negative effects are emerging, including that the government can't play the role of macro-control and supervision effectively, the government can't also give enough support for the local infrastructures construction and the developers escape and delay to pay taxes and wages, and so on. All these negative problems above are restricting the sustainable development of tourism industry.

Based on the SPERE system model, it is known that the relevant interests in the core layer of the scenic area 
development system mainly include the government, developers, local residents and tourists [1]. In China, a large amount of tourism development is pushed through by the local government. On one hand, the local government provides the planning management of the tourism development in the administrative aspects. On the other hand, the local government is the representative of the interests of the whole society [2]. While because of their own rights and the limitations of their values, developers have some unpleasant aspects in the process of tourism exploitation. In order to maximize their benefits, the developers try their bests to look for loopholes in the policy to reduce the cost and enlarge the profit [3]. Therefore, the game between the local government and the developers generates.

Generally speaking, the balance of the interests between both parties in the developing of tourism scenic area is the result of repeated game between interests under the specific resources endowment, policy environment and social conditions [4]. Accordingly, how to coordinate the relationship among stakeholders and to establish the harmonious management system in the development of tourism resources are particularly important. Among those stakeholders, the local government as policy makers and the developers as investors have both played a crucial role in the development, planning, construction and operation of the whole scenic spots. Therefore, understanding the relationship between the local government and the developers is significant for establishing and improving the mechanism among different participants, which then can provide theoretical and practical guidance for the developing and planning of scenic spots in the future.

\section{Game Analysis of the Central and Local Governments}

\subsection{Assumption of the Model}

1) Participants: the local government and the scenic developers. Assumed that both of them are rational, are seeking to maximize collective interests and are also risk neutral.

2) Information: information of the local government and the developers is not entirely symmetrical, whether the unreasonable development and behavior of developers would be oversight and the management by government is unknown. Assumed that:

A: Reasonable development income of the developers;

B: Unreasonable development income of the developers;

C, $D$ : The fixed cost and the variable cost of the government's supervision on developers. The fixed cost "C" is a constant, means that the government will invest a corresponding input on capital and technology regardless of the supervision. The variable cost " $D$ " refers to the additional funds must be invested to make regulatory success, including supervision personnel wages and other labor costs, supervision equipment investment, supervision technology investment, social and legal environment, etc. $D:(L, K, Y, S, Q), L$ refers to supervision personnel wages and other labor costs; $K$ refers to supervision equipment investment; $Y$ refers to supervision technology investment; $S$ refers to social and legal environment; $Q$ refers to other influencing factors. The function relationships between $V$ and $L, K, Y, S, Q$ are:

$$
V=\int(L, K, Y, S, Q)
$$

F: Punishment when the unreasonable development behavior of developers found by the local government;

T: Incomes after the supervision and rectification by government (a comprehensive index, including the protection of tourism ecology environment, enhancement of business performance, improvement of the living environment of local residents, etc.);

$\lambda$ : The probability of the supervision and rectification by the local government;

$\mu$ : The probability of the unreasonable development of the developers.

3) Strategy: Assumed that the local government and the developers both have two strategies, the strategies of the local government including supervision and no supervision; the strategies of the developers including reasonable development and unreasonable development.

4) Payment model (see Table 1).

\subsection{The Game Process}

According to the Game model and parameter:

1) Given $\lambda$, the expected profit of unreasonable development $(\mu=1)$ and reasonable development $(\mu=0)$ of the scenic developers is respectively: 
Table 1. The game model between the local government and the developers.

\begin{tabular}{|c|c|c|c|}
\hline & & \multicolumn{2}{|c|}{ The Local Government } \\
\hline & & Supervision & No supervision \\
\hline \multirow{2}{*}{ The Developers } & Reasonable development & $(A,-C-D)$ & $(A,-C)$ \\
\hline & Unreasonable development & $(B-F,-C-D+T)$ & $(B,-C)$ \\
\hline
\end{tabular}

$$
\begin{aligned}
\pi j(1, \lambda) & =(B-F) \lambda+B \times(1-\lambda) \\
& =B \times \lambda-F \times \lambda+B-B \times \lambda \\
& =B-F \times \lambda, \\
\pi j(0, \lambda) & =A \times \lambda+A \times(1-\lambda)=A
\end{aligned}
$$

If $\pi j(1, \lambda)=\pi j(0, \lambda), B-F \times \lambda=A$

By calculating the equation can be written as:

$$
\lambda=(B-A) / F
$$

We can see from the formula, when the probability of the supervision and rectification of the local government less than $(B-A) / F$, the best choice of the scenic developers is unreasonable development; While when the probability of the supervision and rectification of the local government greater than $(B-A) / F$, the best choice of the scenic developers is reasonable development.

2) Given $\mu$, the expected profit of the local government choosing to supervision $(\mu=1)$ or not $(\mu=0)$ is:

$$
\begin{aligned}
\pi q(1, \mu) & =(-C-D+T) \times \mu+(-C-D) \times(1-\mu) \\
& =-C \times \mu-D \times \mu+T \times \mu-C+C \times \mu-D+D \times \mu \\
& =T \times \mu-C-D, \\
& \pi q(0, \mu)=-C \times \mu+(-C) \times(1-\mu)=-C
\end{aligned}
$$

If $\pi q(1, \mu)=\pi q(0, \mu)$,

By calculating the equation can be written as:

$$
\mu=D / T
$$

We can see from the formula, when the probability of unreasonable development of the scenic developers is greater than $D / T$, the best choice of the local government is supervision and rectification; but when the probability of unreasonable development of the scenic developers is less than $D / T$, the best choice of the local government is not to supervise and rectify.

In summary, we can get mixed strategy game model Nash equilibrium, that is:

$$
\begin{gathered}
\mu=D / T \\
\lambda=(B-A) / F
\end{gathered}
$$

\subsection{Model Solution}

We can get from the game process between the local government and the developers that the mixed strategy game model Nash equilibrium is: $\mu=D / T, \lambda=(B-A) / F$, that is the mixed strategy Nash equilibrium of the scenic management is related to the incomes of reasonable development " $A$ ”, unreasonabe development “ $B$ ”, Punishment " $F$ " and the variable cost of supervision and rectification " $D$ ".

We can see $\lambda=(B-A) / F$ as the function of $B, A, F$, so $\lambda=\lambda(B, A, F)$

Also we can see $\mu=D / T$ as the function of $D, T$, so $\mu=\mu(T, D)$

Thus:

1) $\partial \mu / \partial D>0$, indicates that the higher the variable cost of government's supervision is, the probability of the 
developer's unreasonable development is greater. We can see from the analysis above that $V$ is the function of $L$, $K, S, Y$, so:

a) $\partial \mu / \partial L=(\partial \mu / \partial D) \times(\partial D / \partial L)>0, \partial \mu / \partial K=(\partial \mu / \partial D) \times(\partial D / \partial K)>0$ indicates that with the increase of the supervision and the input of labor and equipment by government to rectify the developers, the probability of the developer's unreasonable development will be larger;

b) $\partial \mu / \partial Y=(\partial \mu / \partial D) \times(\partial D / \partial Y)<0$ indicates that with the enhancement of the local government's supervision technology, the probability of the developer's unreasonable development will be less;

c) $\partial \mu / \partial S=(\partial \mu / \partial D) \times(\partial D / \partial S)<0$ indicates that with the improvement of social and legal environment, the probability of the developer's unreasonable development will be less.

2) $\partial \mu / \partial T<0$ indicates that the greater the achievement of the local government's supervision is, the less the probability of the developer's unreasonable development will be;

3) $\partial \lambda / \partial B>0$ indicates that the more the incomes of unreasonable development are, the more attractive to the developers will be;

4) $\partial \lambda / \partial B<0, \partial \lambda / \partial F<0$ means when the loss of developers by the supervision of the local government is higher, the probability of the developer's unreasonable development will be less.

\section{Conclusions and Recommendations}

This paper starts from the needs of the interests between the local government and the developers, constructing a game model for the scenic sustainable development to make clear the decision-making behavior of both parties and the balance of interests in the game process. Through the game process, we can see that reducing the probability of the developers' unreasonable development and enhancing the power of the local government's supervision are key steps for the scenic sustainable development.

\subsection{The Local Government Should Establish the Guarantee Mechanism}

First of all, the local government should fulfill the functions of supervision and management. In the construction project, the local government needs to carry out the strict examination and approval and make relevant argumentation to ensure that the project construction will be benefit to the local community. In the choice of investment enterprises, the government should adopt public bidding impartially, fairly and reasonably to find the most suitable investment enterprises. In the management of the investment enterprises, the local government should supervise the development behavior strictly, set the industry specifications and make the evaluation of the impact of tourism. Second, the local government should give full consideration to the parties involved in the development of requirements to resources' using rights and distribution rights, and regulate the way of utilization of resources, so as to ensure the smooth progress of tourism development. Third, the local government should also be together with other management departments and non-governmental organizations to consult and formulate relevant policies, to standardize the conduct of the parties involved in the development and to ensure the smooth development of tourism.

\subsection{Strengthen and Improve the Supervision Mechanism to the Local Government and the Developers}

On one hand, the local government needs to reduce the cost of supervision and rectification; on the other hand, the whole society should strengthen its power of supervision, make social workers and local residents that supervise those scenic developers voluntarily and establish a diversification supervision mechanism. Specifically, the local government should encourage the scenic residents to report and expose the illegal operation behavior of developers and give appropriate rewards for such behavior. Also, the local government could open the hotline of the environment quality assessment and encourage visitors to provide feedback and suggestions to the tourism supervision department. What's more, the local government can cooperate with related media and encourage them to report the management activities in order to fully play the role of media's power of supervision and management. Fourth, as the more perfect the protection system and law are, the possibility of developers' unreasonable exploitation will be smaller, so it is necessary to establish and improve the policies and laws of tourism scenic protection. Fifth, the local government should improve the efficiency of the supervision and management. 


\section{References}

[1] Zhou, T.Q. (2004) Development and Management of Tourism Scenic Spots. Tsinghua University Publishing Ltd., Beijing.

[2] Guo, H. (2008) Review and Revelation of Foreign Tourism Stakeholders. Human Geography, 2, 100-105

[3] Zhou, N.X., Yu, K.J. and Li, D.H. (2005) The Stakeholders' Analysis in the Planning of the Scenic Spots. Economic Geography, 25, 716-719

[4] Zhang, W.Y. (2012) Game Theory and Information Economics. Gezhi Publishing Ltd., Shanghai. 
Scientific Research Publishing (SCIRP) is one of the largest Open Access journal publishers. It is currently publishing more than 200 open access, online, peer-reviewed journals covering a wide range of academic disciplines. SCIRP serves the worldwide academic communities and contributes to the progress and application of science with its publication.

Other selected journals from SCIRP are listed as below. Submit your manuscript to us via either submit@scirp.org or Online Submission Portal.
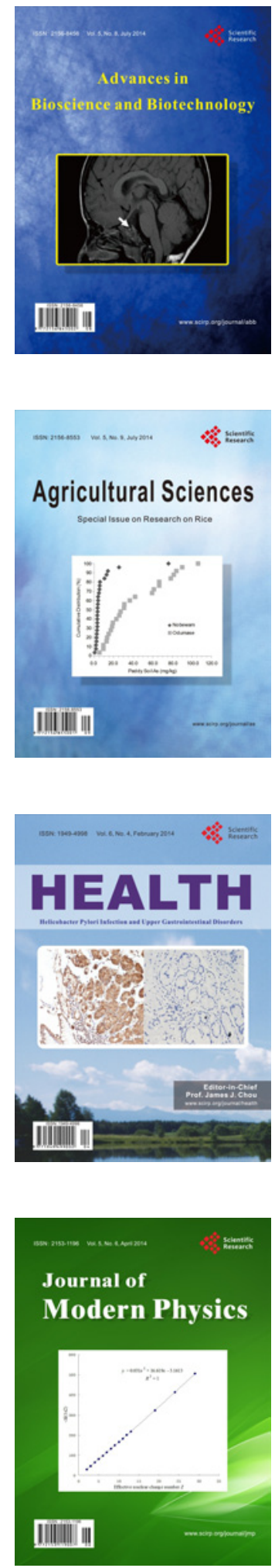
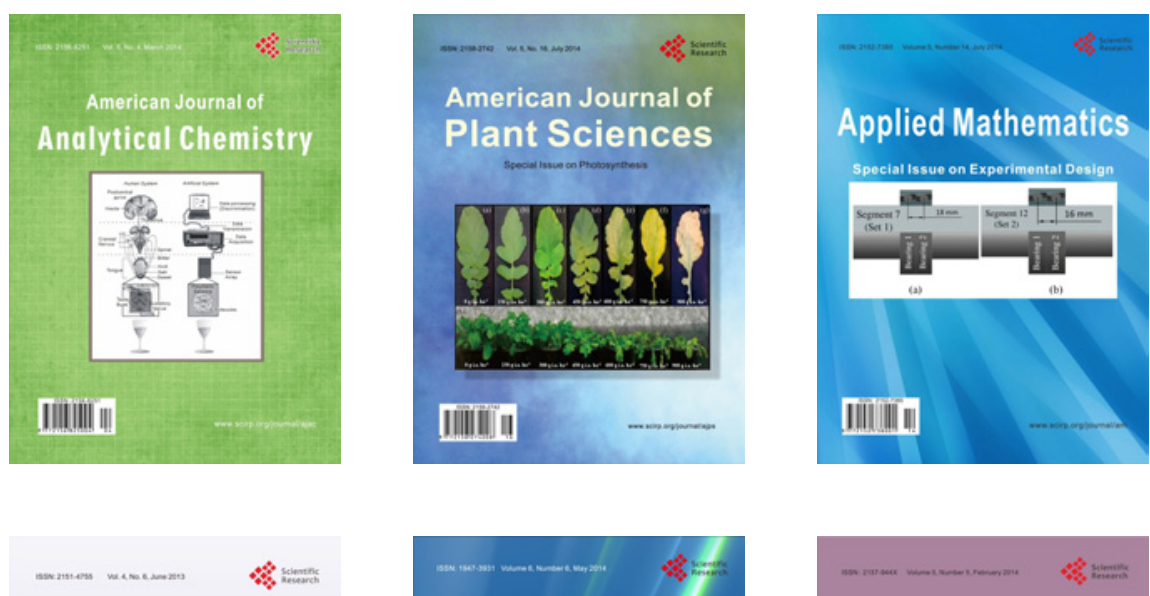

Creative Education
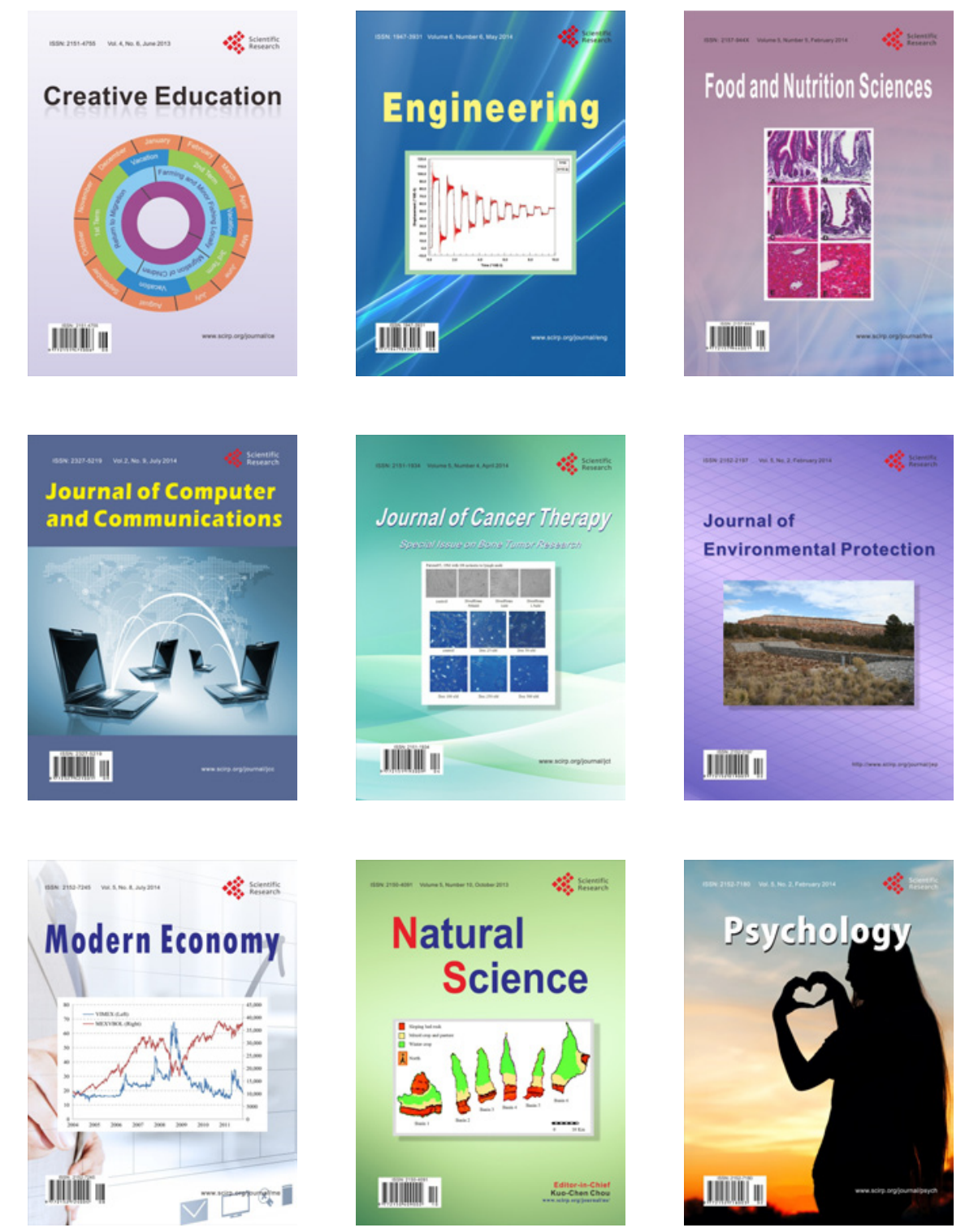